\title{
Functional and radiological evaluation of surgical management in tibial plateau fractures: a prospective study
}

\author{
Sreenath Rao Jakinapally ${ }^{1}$, Sridhar Reddy Konuganti ${ }^{2} *$, Vennamaneni Pratish Rao $^{3}$, \\ Sivaprasad Rapur ${ }^{4}$
}

\begin{abstract}
Department of Orthopedics, ${ }^{1}$ Maxcure Hospital, Sarovar Complex, Secretariat Road, Saifabad, ${ }^{2}$ Maheshwara Medical College and Hospital, Chitkul(V), Patancheru, Medak, ${ }^{3}$ Government Medical college and Hospital , Siddipet, ${ }^{4}$ Mediciti Institute of Medical Sciences, Ghanpur, Medchal, Telangana, India
\end{abstract}

Received: 25 January 2018

Accepted: 15 February 2018

\section{*Correspondence:}

Dr. Sridhar Reddy Konuganti,

E-mail: sridhara983@gmail.com

Copyright: (c) the author(s), publisher and licensee Medip Academy. This is an open-access article distributed under the terms of the Creative Commons Attribution Non-Commercial License, which permits unrestricted non-commercial use, distribution, and reproduction in any medium, provided the original work is properly cited.

\section{ABSTRACT}

Background: Tibial plateau fractures affect knee which is a major weight bearing joint, altering its contribution to stability and its function. Regardless of the advancements in technique and implants, ideal mode of management is still contentious.

Methods: This prospective study reviewed 20 consecutive cases of tibial plateau fractures managed surgically by various modes of internal fixation from November 2012 to June 2014 in the Department of orthopaedics at Mediciti Institute of medical sciences, Ghanpur, Medchal, a tertiary care referral and trauma center.

Results: This study comprised higher number of fractures type II and type IV Schatzker classification, with mean age of 37.75 years. Most frequent mode of injury is Road traffic accident in $n=17$ out of $n=20$ patients $(85 \%)$. Mean gain in flexion of 113.33 degree. Mean score of 27.15 and 9.70 under modified Rasmussen criteria for clinical assessment and radiological assessment respectively at 6 months.

Conclusions: Optimal outcome from surgical care of tibial plateau fracture is acquired when precise articular surface reconstruction with elevation of depressed bone fragment, and bone grafting when necessary, associated with rigid fixation which permits early physiotherapy and return to function. Deficiency of excellent results among type $\mathrm{V}$ and type VI fractures are often secondary to inadequate reconstruction and collapse of articular restoration post operatively.

Keywords: Surgical management, Tibial plateau fractures, Modified Rasmussen criteria, Schatzker classification

\section{INTRODUCTION}

Tibial plateau is a major load bearing area and any fractures involving tibial plateau often disturb the stability, alignment and articular congruence of knee joint. Approach to the surgical management should be based on age of patient, level of activity, associated medical conditions, and expectations of patient. These account for nearly $1 \%$ of fractures occurring in adults. ${ }^{1}$ The Schatzker classification is an accepted system routinely adopted to classify fractures based on morphology of fracture radiologically and is often used to standardize treatment. ${ }^{2}$ Improvements in trauma care lead to sophisticated interpretation of biomechanics, parameters of implant design, soft tissue care, and fundamentals of internal fixation have paved way for internal fixation as a superior practice over conservative approach. Yet these fractures remain demanding secondary to high variance in presentation. The objective of this study is to review the outcome of surgical management in tibial plateau fracture in terms of clinical and radiological assessment utilizing modified Rasmussen criteria at 6 months. ${ }^{3}$ 


\section{METHODS}

This prospective study reviewed 20 consecutive cases of tibial plateau fractures managed surgically by various modes of internal fixation from November 2012 to June 2014 in the Department of Orthopaedics at Mediciti Institute of Medical Sciences, Ghanpur, Medchal, a tertiary care referral and trauma centre.

\section{Inclusion criteria}

Inclusion criteria were all patients with acute tibial plateau fractures; age group of 18 and above years of both sexes.

\section{Exclusion criteria}

Exclusion criteria were patients with malunited tibial plateau fractures treated elsewhere; patients with significant comorbid conditions which rule out surgical management; patients with concomitant neurovascular injury.

\section{Approach}

Brief history is taken and patient's condition is assessed through clinical examination and intensive care was given to those patients who presented with shock. Once the patient's general condition was fair, necessary radiographs are advised. Sophisticated investigations such as CT scan are advised whenever necessary. Fractures are classified using Schatzker's classification. Fractures are designated to be unstable if they present with any Depression greater than $4 \mathrm{~mm}$ or displacement greater than $10 \mathrm{~mm}$ or Instability greater than 10 degree. Fixation can be done with $6.5 \mathrm{~mm}$ non cannulated or cannulated cancellous screw, $4.5 \mathrm{~mm}$ cortical screws, T or L-buttress plate, $\mathrm{T}$ or L locking plate, recon plate with bone grafting when required. The bone graft was harvested from ipsilateral iliac crest.

Mode of treatment depends on type of fracture, extent of displacement and depression of tibial plateau. The patients were taken to surgery at the earliest possible time depending on their medical condition, skin condition and the amount of swelling. Intraoperative $\mathrm{C}$-arm image intensifier is used.

Postoperatively knee mobilization and static quadriceps exercises were started on the 3rd day; non-weight bearing ambulation for 3 weeks, followed by non-weight bearing ambulation with crutch up to 6 weeks and after 6 weeks weight bearing as tolerated with crutch. Antibiotics were given 2 days intravenously and 3 days orally. The suture removal was done after $12^{\text {th }}$ postoperative day. X-ray was done on first post-operative day and later on repeated at 6 weeks, 3 months and 6 months.
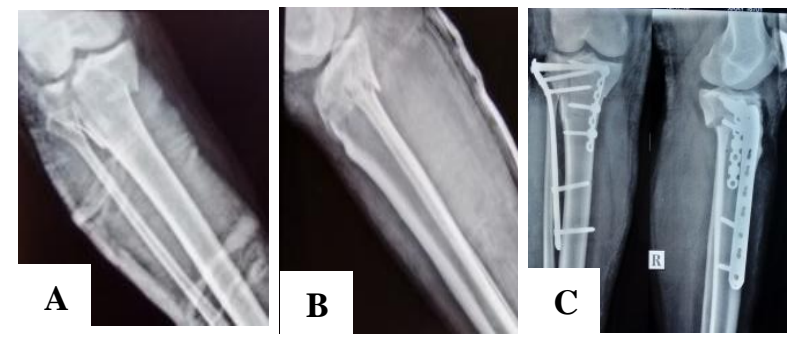

Figure 1 (A-C): Pre op and post op radiographs of Schatzker type $\mathbf{V}$ fracture treated with dual plating.

\section{Follow up}

The follow up was done at 2 weeks, 6 weeks, 3 months, 6 months. Assessment at 6 months is done using modified Rasmussen's criteria.

Table 1: Clinical assessment.

\begin{tabular}{|ll|}
\hline Pain & \\
\hline None & 6 \\
\hline Occasional & 5 \\
\hline Stabbing pain in certain position & 3 \\
\hline Constant pain after activity & 1 \\
\hline Significant rest pain & -3 \\
\hline Walking capacity & \\
\hline Normal walking capacity for age & 6 \\
\hline Walking outdoors more than one hour & 5 \\
\hline Walking outdoor 15 mins -1 hour & 3 \\
\hline Walking outdoor $<15$ mins & 1 \\
\hline Walking indoor only & 0 \\
\hline Knee extension & \\
\hline Lack of extension $<10^{0}$ & 2 \\
\hline Lack of extension $>10^{0}$ & 0 \\
\hline Lack of extension $>20^{0}$ & -2 \\
\hline Total range of motion & \\
\hline Full & 6 \\
\hline At least $120^{0}$ & 5 \\
\hline At least $90^{0}$ & 3 \\
\hline At least $60^{\circ}$ & 1 \\
\hline$<60^{0}$ & -3 \\
\hline Stability & \\
\hline $\begin{array}{l}\text { Normal stability in extension and } 20^{0} \\
\text { flexion }\end{array}$ & 6 \\
\hline Abnormal instability in $20^{\circ}$ flexion & 4 \\
\hline Instability in extension $<10^{0}$ & 2 \\
\hline Instability in extension $>10^{0}$ & 0 \\
\hline Power of quadriceps & 28 \\
\hline Grade 5 & $24-27$ \\
\hline Grade 3-4 & $20-23$ \\
\hline Grade $<3$ & $<20$ \\
\hline Maximum score & \\
\hline Excellent & 30 \\
\hline Good & \\
\hline Fair & \\
\hline Poor & \\
\hline & \\
\hline
\end{tabular}


Table 2: Radiological assessment.

\begin{tabular}{|ll|}
\hline Articular depressions & \\
\hline None & 3 \\
\hline$<5 \mathrm{~mm}$ & 2 \\
\hline $6-10 \mathrm{~mm}$ & 1 \\
\hline$>10 \mathrm{~mm}$ & 0 \\
\hline Condylar widening & 3 \\
\hline None & 2 \\
\hline$<5 \mathrm{~mm}$ & 1 \\
\hline $6-10 \mathrm{~mm}$ & 0 \\
\hline$>10 \mathrm{~mm}$ & \\
\hline Valgus varus angulation & 3 \\
\hline None & 2 \\
\hline$<10^{0}$ & \\
\hline $10^{0}-20^{0}$ & 0 \\
\hline$>20^{0}$ & \\
\hline Osteoarthrosis & 1 \\
\hline None/no progress & 0 \\
\hline Progression by 1 grade & -1 \\
\hline Progression by $>1$ grade & \\
\hline Out come & $9-10$ \\
\hline Excellent & $7-8$ \\
\hline Good & $5-6$ \\
\hline Fair & $<5$ \\
\hline Poor & \\
\hline
\end{tabular}

The statistical analysis was done applying PSPP version 1.0.1.

\section{RESULTS}

Our study comprised of 20 patients, 15 were males and 5 were females. The age of patients ranged from 20 years to 71 years, with mean age of 37.75 years.

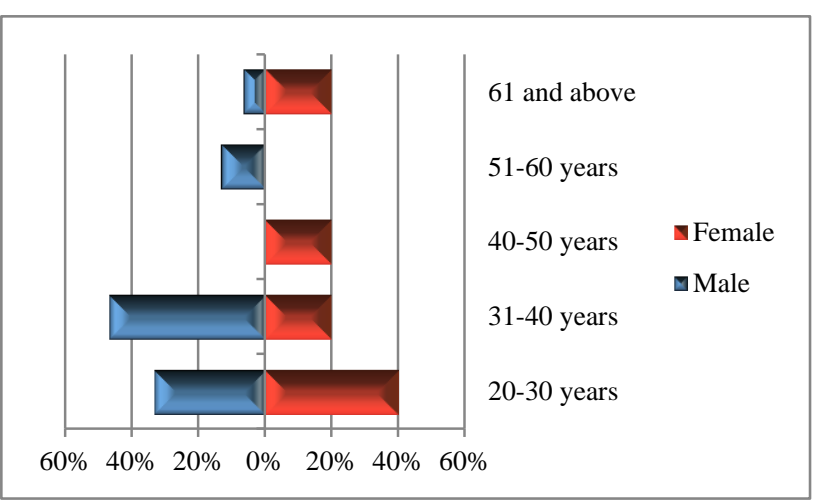

Figure 2: Age distribution based on gender.

The most frequent mode of injury was road traffic accident in 17 patients, $(85 \%)$, against fall from height in 3 patients, (15\%).

Incidence of fracture in laborer is $\mathrm{n}=8,(40 \%)$, employee $\mathrm{n}=6(20 \%)$, homemaker $\mathrm{n}=4,(20 \%)$, and businessman $\mathrm{n}=2,(10 \%)$.

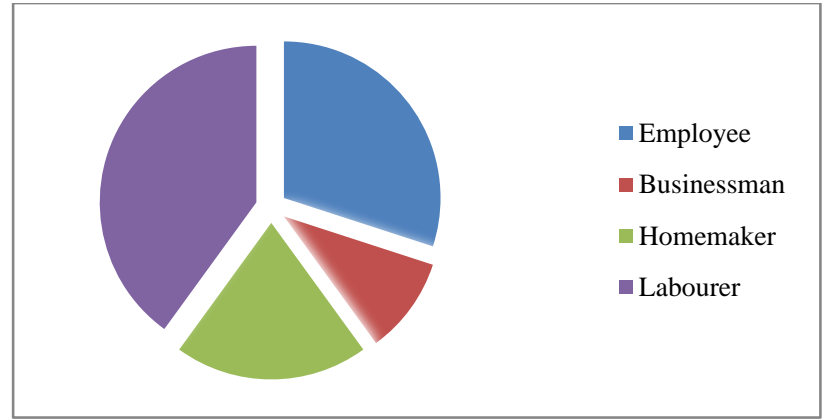

Figure 3: Distribution as per occupation.

In our study, $\mathrm{n}=12(60 \%)$ out of 20 patients experienced injury to left limb and in $n=8(40 \%)$ right limb is involved.

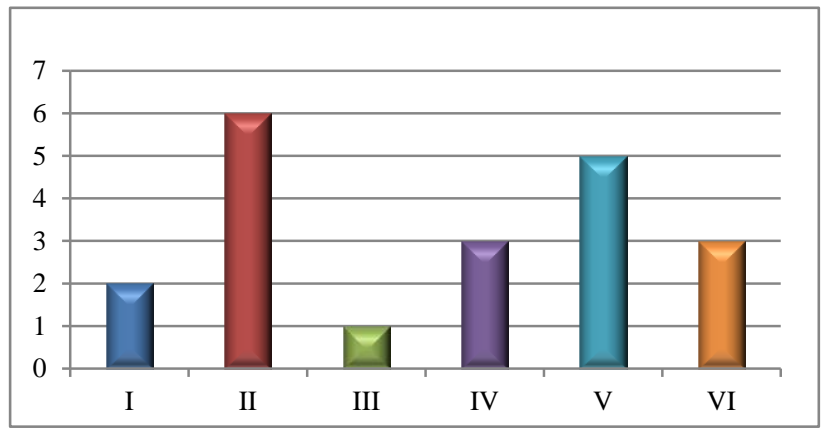

Figure 4: Frequency of fracture type.

Out of the 20 cases, according to Schatzker classification, $\mathrm{n}=2(10 \%)$ were type I fractures, $\mathrm{n}=6(30 \%)$ were type II fractures, $n=1(5 \%)$ was type III fractures, $n=3(15 \%)$ were type IV fractures, $\mathrm{n}=5(25 \%)$ were type $\mathrm{V}$ fractures, $\mathrm{n}=3(15 \%)$ were type VI fractures.

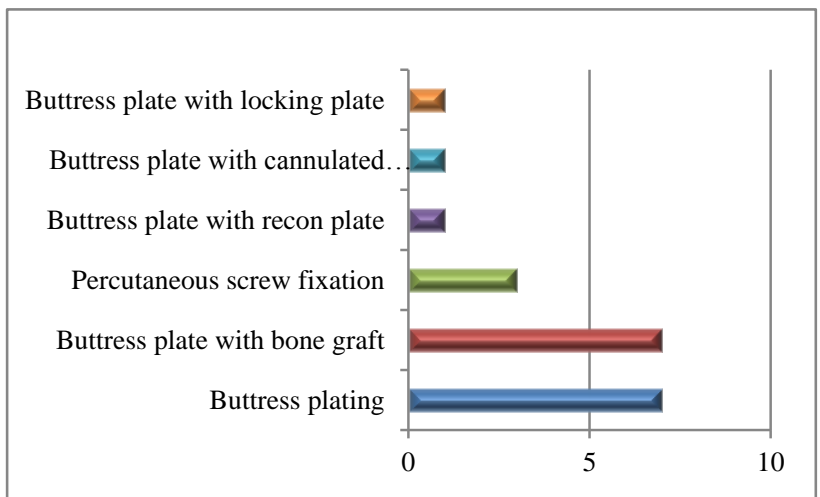

Figure 5: Frequency of method of treatment.

Of the 20 cases, $n=3 \quad(15 \%)$ were managed with percutaneous cancellous screw fixation, $n=7(35 \%)$ cases were treated by Open reduction internal fixation (ORIF) with buttress plate, $\mathrm{n}=7(35 \%)$ were treated with ORIF with buttress plate and bone graft, one case $(n=1,5 \%)$ managed with ORIF with buttress plating and recon plate, one case $(n=1,5 \%)$ managed with ORIF with buttress 
plating and cannulated cancellous screw fixation, one case $(n=1,5 \%)$ managed with buttress plate and locking compression plate. Mean flexion attained was 113.33 degree.

Table 3: Complications.

\begin{tabular}{|lll|}
\hline Complications & $\begin{array}{l}\text { No. of } \\
\text { cases (n) }\end{array}$ & $\begin{array}{l}\text { Percentage } \\
(\%)\end{array}$ \\
\hline Knee stiffness & 2 & 10 \\
\hline $\begin{array}{l}\text { Valgus and varus } \\
\text { deformity }\end{array}$ & 1 & 5 \\
\hline $\begin{array}{l}\text { Infection and wound } \\
\text { dehiscence }\end{array}$ & 1 & 5 \\
\hline
\end{tabular}

In our study $\mathrm{n}=9,(45 \%)$, cases had excellent outcome, $\mathrm{n}=7,(35 \%)$, cases had good outcome, $\mathrm{n}=3,(15 \%)$, cases had fair outcome and $n=1,(5 \%)$, case had poor outcome.

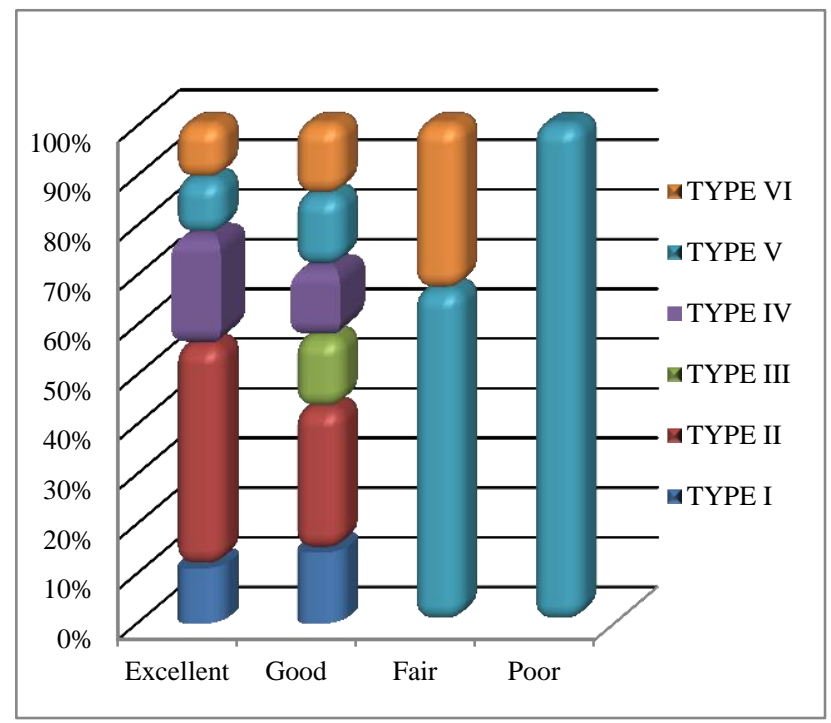

Figure 6: Composition of outcome in percentage of type of fracture.

\section{DISCUSSION}

The expeditious industrialization and mechanization lead to increase in number of automobiles and as a consequence increase in the number of high velocity accidents occurring in a population. Often in high energy trauma associated bony and soft tissue injuries increase the chances of residual morbidity and present a challenge to surgeons.

In our study, tibial plateau fractures were more prevalent in the active age group 20 to 40 years $(n=15,75 \%)$. The mean age for cases affected by road traffic accident is 35.65 years against the mean age for cases affected by fall from height is 49.67 years, which can be attributed to higher road traffic accidents in young age group. The mean age is 37.75 years in our study is comparable to 39.8 years in Honkonen et al and 40 years in Stevens et al. $^{4,5}$
Our study comprised $75 \%$ males which is similar to $76 \%$ in Unnikrishnan et al and $79 \%$ in Jain et al. ${ }^{6,7}$

RTA as a mode of injury was $85 \%$ in our study comparable to $86 \%$ in Manidakis et al as opposed to $55 \%$ in Rademakers et al. ${ }^{8,9}$

In our study it is seen that individuals with higher daily commutation are at more risk as they comprised $70 \%$ of sample size [laborer is $n=8,(40 \%)$, employee $n=6(20 \%)$ and businessman $n=2,(10 \%)]$.

In our study, left limb was involved in $n=12(60 \%)$, showing there was marginal left sided predominance.

Schatzker's type II and type V fractures accounted for $\mathrm{n}=11(55 \%)$ of sample size, showing a higher incidence. In our study, distribution of patients as per Schatzker classification was comparable to Mytatt et al. ${ }^{10}$

Table 4: Distribution of fracture type in the study.

\begin{tabular}{|lll|}
\hline Schatzker type & Mytatt $^{\mathbf{1 0}}$ & Our study (\%) \\
\hline I & $7.5 \%$ & 10 \\
\hline II & $30 \%$ & 30 \\
\hline III & $2.5 \%$ & 5 \\
\hline IV & $20 \%$ & 15 \\
\hline V & $27.5 \%$ & 25 \\
\hline VI & $12.5 \%$ & 15 \\
\hline
\end{tabular}

$55 \%$ of patients had type IV, V and VI fractures which follow high energy trauma correlating with Road traffic accidents being major mode of injury in our study.

In our study $20 \%$ of the patients had complications which were comparable to $19 \%$ in Moore et al and Jain et al. ${ }^{7,11}$

Of the type I fracture $50.00 \%$ had excellent and $50.00 \%$ had good outcome. Of the type II fracture $66.67 \%$ had excellent and $33.33 \%$ had good outcome. Of the type III fracture $100.00 \%$ had excellent outcome. Of the type IV fracture $66.67 \%$ had excellent and $33.33 \%$ had good outcome. Of type V $20.00 \%$ had excellent outcome, $20.00 \%$ good outcome, $40.00 \%$ fair outcome and $20.00 \%$ poor outcome. Type VI had $33.33 \%$ excellent, good and fair outcome each. Fair and poor outcomes are seen in Schatzker type V and VI, from which it can be interpreted that fractures are difficult to treat as the complexity of fracture increases.

\section{CONCLUSION}

Better outcomes validate surgical management of tibial plateau fractures. The objective of surgery is to attain accurate anatomic reduction and rigid fixation so as to allow early restoration of function. Fracture morphology and soft tissue condition dictate the selection of procedure. Early return to function is possible by firm adherence to physiotherapy regimen. 
Funding: No funding sources

Conflict of interest: None declared

Ethical approval: The study was approved by the institutional ethics committee

\section{REFERENCES}

1. Albuquerque PR, Hara R, Prado J, Schiavo 1, Giordano V, Pecegueiro do Amaral N. Epidemiological study on tibial plateau fractures at a level I trauma centre. Acta Ortopedica Brasileira. 2013;21(2):109-15.

2. Schatzker J, McBroom R, Bruce D. The Tibial plateau fracture: the Toronto experience 1968-1975. Clin Orthop Rel Res. 1979;138:94-104.

3. Rasmussen PS. Tibial condylar fractures. J Bone Joint Surg. 1973;55(7):1331-50.

4. Honkonen SE. Indications for surgical treatment of tibial condyle fractures. Clin Orthop. 1994;302:199205.

5. Stevens DG, Beharry R, McKee MD, Waddell JP, Schemitsch EH. The long-term functional outcome of operatively treated tibial plateau fractures. J Orthopaed Trauma. 2001;15(5):312-20.

6. Unnikrishnan J, Jacob PJ, Francis J. Functional outcome of tibial condyle fractures following open reduction and internal fixation with plate and screws. Kerala J Orthopaed. 2013;26(2):98-106.
7. Jain RK, Shukla R, Baxi M, Agrawal U, Yadav S. Evaluation of functional outcome of tibial plateau fractures managed by different surgical modalities. Int J Res Orthop 2016;2:5-12.

8. Manidakis N, Dosani A, Dimitriou R, Stengel D, Matthews S, Giannoudis P. Tibial plateau fractures: functional outcome and incidence of osteoarthritis in 125 cases. Int Orthop. 2010;34(4):565-70.

9. Rademakers MV, Kerkhoffs GM, Sierevelt IN, Raaymakers EL, Marti RK. Operative treatment of 109 tibial plateau fractures: five-to 27 -year followup results. J Orthop Trauma. 2007;21:5-10.

10. Myatt RW, Miles J, Matharu GJ, Cockshott S, Kendrew J. The Financial Cost of Managing Tibial Plateau Fractures at a Major Trauma Centre. Trauma. 2014;17(1):33-8.

11. Moore TM, Patzakis MJ, Harvey JP. Tibial plateau fractures: definition, demographics, treatment rationale, and long-term results of closed traction management or operative reduction. J Orthopaed Trauma. 1987;1(2):97-119.

Cite this article as: Jakinapally SR, Konuganti SR, Rao VP, Rapur S. Functional and radiological evaluation of surgical management in tibial plateau fractures: a prospective study. Int J Res Orthop 2018;4:261-5. 